02

\title{
Люминесценция квантовых точек CdS : Ag в матрице полиметилметакрилата
}

\author{
(C) В.П. Смагин ${ }^{1}$, Н.С. Еремина ${ }^{2}$, А.Г. Скачков ${ }^{1}$ \\ ${ }^{1}$ Алтайский государственный университет, \\ 656049 Барнаул, Россия \\ 2 Томский государственный университет, \\ 643050 Томск, Россия \\ e-mail: smaginV@yandex.ru
}

Поступила в редакцию 14.12.2017 г.

Полупроводниковые квантовые точки (КТ) интенсивно люминесцируют и воспроизводят оптические характеристики. Легирование ионами металлов положительно влияет на их свойства. Внедрение КТ в полимерные матрицы приводит к формированию требуемой морфологии композиций. Проблема синтеза оптически прозрачных полимерных композиций, содержащих КТ группы $\mathrm{A}^{2} \mathrm{~B}^{6}$, заключается в крайне малой растворимости халькогенидов металлов и большинства их предшественников в мономерах. Для ее решения нами применен коллоидный синтез. КТ CdS были получены методом возникающих реагентов in situ в среде метилметакрилата (MМA). Легирование ионами $\mathrm{Ag}^{+}$проведено введением в реакционную смесь соли серебра в процессе синтеза КТ CdS. Люминесцирующие полимерные „стекла“ ПММA/CdS: Ag получены радикальной полимеризацией ММА в блоке. Прозрачность композиций при длинах волн $>500 \mathrm{~nm}$ достигает 92\% $(5 \mathrm{~mm})$. Возбуждение люминесценции связано с межзонными переходами электронов в кристаллах $\mathrm{CdS}$. Люминесценция в области 500-600 nm наблюдается при возвращении электронов через систему уровней в запрещенной зоне легированных кристаллов CdS. Положение спектральных полос и их интенсивность зависят от концентрации $\mathrm{Ag}^{+}$, размера частиц, длины волны возбуждающего излучения и других факторов. Образование структур $\mathrm{Cd}(\mathrm{Ag}) \mathrm{S} / \mathrm{Ag}_{2} \mathrm{~S}$ при концентрациях ионов $\mathrm{Ag}^{+}>5.0 \cdot 10^{-3} \mathrm{~mol} / \mathrm{L}$ тушит люминесценцию.

DOI: $10.21883 /$ OS.2018.05.45944.292-17

\section{Введение}

Наноразмерные кристаллы полупроводников (КТ) применяются для решения важных задач в приборостроении, биологии, экологии, медицине [1-3]. В связи с этим значительные усилия исследователей направлены на разработку методов синтеза КТ, их структур и композиций, характеризующихся набором прогнозируемых оптических характеристик. Одними из наиболее изученных являются КТ халькогенидов металлов. Их синтезируют в виде порошков, пленок, в растворах, вводят в состав различных матриц [4-9]. Размер КТ, как правило, находится в пределах $10 \mathrm{~nm}$. Их агрегаты достигают размера десятков нанометров $[7,10,11]$. Люминесценцию КТ связывают с излучательной рекомбинацией зарядов на уровнях структурно-примесных дефектов в объеме и на поверхности кристаллов [3-6]. Легирование кристаллов существенно изменяет их оптические свойства. В качестве легирующих элементов применяются медь, марганец, хром, свинец, лантаноиды [1,11-19]. Кроме перечисленных, привлекает внимание серебро и его соли. Так, сульфид серебра относится к узкозонным полупроводникам с шириной запрещенной зоны 0.9-1.1 eV. Его применяют в фотогальванических элементах, фотохимических ячейках, ИК детекторах, в светопреобразующих композициях [20-22]. Легирование КТ полупроводников группы $\mathrm{A}^{2} \mathrm{~B}^{6}$ ионами серебра неизбежно приведет к изменению энергетической диаграммы полупроводниковых структур и окажет влияние на направление потоков энергии в процессе дезактивации возбужденных состояний.

Важной задачей, которую приходится решать в процессе синтеза, является сохранение устойчивости КТ и связанной с ней стабильности оптических характеристик. Одним из ее решений является внедрение КТ в полимерные матрицы. Этот способ позволяет зафиксировать пространственное положение КТ и сформировать необходимую морфологию композиций [23-25]. Не менее сложная задача заключается в сохранении оптической прозрачности гетерогенных композиций. Одним из перспективных способов решения этой задачи является коллоидный синтез. При его проведении КТ могут быть получены in situ в среде мономера, который одновременно является предшественником основы композиций, а также реакционной средой синтеза КТ и их структур и дисперсионной средой образующегося коллоидного раствора [10,26].

Решение обозначенных задач создает предпосылки разработки технологичных полимерных композиций с прогнозируемым набором оптических характеристик для оптоэлектроники, приборостроения, машиностроения.

Исходя из этого цель данной работы заключалась в синтезе и установлении зависимости спектральнолюминесцентных свойств КТ легированного $\mathrm{CdS}$ в матрице (поли)метилметакрилата (ПММА) от концентра- 
ции ионов $\mathrm{Ag}^{+}$, размера частиц, длины волны возбуждающего излучения, а также в определении влияния полимерной матрицы на люминесценцию композиций ПММА/CdS: Ag.

\section{Экспериментальная часть}

КТ сульфида кадмия, легированного ионами серебра, были синтезированы в среде метилметакрилата (MМА, Merck) взаимодействием трифторацетатов кадмия и серебра с тиоацетамидом (ТАА) при нагревании аналогично [11]. Концентрация трифторацетата кадмия и TAА во всех растворах была равна $0.010 \mathrm{~mol} / \mathrm{L}$. Концентрацию трифторацетата серебра изменяли от нуля до $0.010 \mathrm{~mol} / \mathrm{L}$, что соответствует изменению мольных соотношений $\mathrm{Cd}: \mathrm{Ag}$ от 1:0 до 1:1. Об образовании КТ судили по появлению характерной для $\mathrm{CdS}$ желтозеленой окраски. Опалесценция растворов указывала на их коллоидную природу.

В стеклообразное состояние коллоидные растворы переведены радикальной полимеризацией ММА в блоке аналогично [27]. Для этого в растворы вводили перекись бензоила (ПБ) в количестве $0.10 \%$ от массы ММА и нагревали при температуре $60-70^{\circ} \mathrm{C}$ до вязкого состояния. Вязкими растворами заполняли разборные стеклянные кюветы и продолжали нагревать до перехода композиций в стеклообразное состояние. При малых концентрациях ионов $\mathrm{Ag}^{+}$прозрачные „стекла“ имели желто-зеленую окраску сульфида кадмия. При увеличении в реакционной смеси концентрации трифторацетата серебра $>5.0 \cdot 10^{-3} \mathrm{~mol} / \mathrm{L}$ ее окраска постепенно становилась коричневой. Появление коричневой окраски связано с образованием структур $\mathrm{Cd}(\mathrm{Ag}) \mathrm{S} / \mathrm{Ag}_{2} \mathrm{~S}$.

Спектры поглощения композиций зарегистрированы на спектрофотометре Specord UF VIS в диапазоне 250-800 nm относительно воздуха, пластин немодифицированного ПММА и ПММА/CdS сопоставимых толщин. Спектры возбуждения люминесценции и люминесценции записаны на спектрофлуориметре СМ 2203 („Solar“, Республика Беларусь). Возбуждающий свет источника излучения (ксеноновая дуговая лампа высокого давления ДКсШ 150-1М) падал на образец перпендикулярно его поверхности. Стационарную люминесценцию регистрировали под углом $45^{\circ}$. Спектры возбуждения люминесценции регистрировали для излучения в области максимума полосы в спектре люминесценции. Для исследования использовали образцы равной толщины.

\section{Результаты и их обсуждение}

ПММА интенсивно поглощает излучение в УФ области спектра с длиной волны $<300 \mathrm{~nm}$. Ниспадающая ветвь полосы поглощения распространяется до $400 \mathrm{~nm}$. В видимой части спектра при толщине полимерных пластин до $5 \mathrm{~mm}$ пропускание ПММА достигает 92-93\%.
Пропускание пленок ПММА сопоставимо с пропусканием силикатных стекол. В спектрах композиций ПММА/CdS, зарегистрированных относительно ПММА, наблюдается широкая сложная полоса в интервале длин волн 280-470 $\mathrm{nm}$ с размытым максимумом в области 350-380 nm. Она отнесена к поглощению наночастиц $\mathrm{CdS}$. Размер частиц $\mathrm{CdS}$, рассчитанный из спектроскопических данных, составляет $\sim 3.1 \mathrm{~nm}$. Он соответствует результатам, полученным методом просвечивающей электронной микроскопии (ПЭМ) $[11,18,26]$. В спектрах композиций ПММА/CdS: Ag увеличивается интенсивность длинноволновой компоненты полосы поглощения $\left(A_{\max }=0.692+110 C_{\mathrm{Ag}}\right)$. При этом ее максимум смещается от 412 до $420 \mathrm{~nm}$. Точка пересечения касательных с осью абсцисс, проведенных к ниспадающей ветви полосы поглощения, также смещается в область длинных волн. Батохромное смещение связано с увеличением размера частиц при внедрении ионов $\mathrm{Ag}^{+}$в структуру кристаллов $\mathrm{CdS}$, а также при образовании оболочки сульфида серебра $\left(\mathrm{Cd}(\mathrm{Ag}) \mathrm{S} / \mathrm{Ag}_{2} \mathrm{~S}\right)$, покрывающей сульфид кадмия. На это указывает увеличение фонового поглощения в области длинных волн в спектрах композиций, полученных из растворов с концентрацией соли серебра $>5.0 \cdot 10^{-3} \mathrm{~mol} / \mathrm{L}$. Окраска полимерных композиций изменяется с желто-зеленой на коричневую, усиливающуюся с увеличением концентрации ионов $\mathrm{Ag}^{+}$.

Люминесценция ПММА проявляется в спектральной области 400-470 nm. Соответствующая полоса в спектре возбуждения люминесценции находится в интервале длин волн $300-380 \mathrm{~nm}\left(\lambda_{L}=440 \mathrm{~nm}\right)$. Интенсивность полос невысокая. Их появление связано с продуктами разложения перекиси бензоила, которую в небольшом количестве вводили в реакционную смесь для инициирования полимеризации ММА.

Композиции ПММА/CdS люминесцируют в спектральной области 550-750 nm. В спектре люминесценции наблюдается широкая сложная полоса. Ее связывают с образованием вакансионных комплексов на поверхности наноразмерных кристаллов $\mathrm{CdS}$. В запрещенной зоне $\mathrm{CdS}$ комплексы формируют энергетические уровни, играющие роль электронных ловушек [12,28,29]. Положение максимума полосы люминесценции в зависимости от условий синтеза изменяется в интервале от 600 до $700 \mathrm{~nm}$. Ее смещение объясняется усилением роли примесных донорно-акцепторных переходов в условиях комплексообразования на поверхности кристаллов $\mathrm{CdS}$. Образование слоя комплексных соединений на поверхности КТ подтверждено результатами ПЭМ [11,29]. При нагревании композиций в процессе синтеза комплексы разрушаются. Продолжается образование сульфида кадмия. Полоса люминесценции $\mathrm{CdS}$ смещается в коротковолновую часть спектра. В спектре возбуждения люминесценции регистрируется широкая полоса в интервале длин волн 290-460 nm. Значительная ширина полос в спектрах возбуждения и люминесценции связана с неоднородностью структуры и поверхности частиц, 
а также с дисперсностью. Кроме того, на спектр оказывает влияние кислород, который относительно легко замещает ионы серы в узлах кристаллической решетки, создавая дополнительные дефекты в структуре полупроводника [30]. Следует отметить, что полоса возбуждения люминесценции ПММА/CdS перекрывается с полосой возбуждения люминесценции ПММА, а ее длинноволновой участок накладывается на полосу люминесценции ПММА. Из этого можно предположить реабсорбцию излучения матрицы кристаллами $\mathrm{CdS}$.

B спектре люминесценции композиций ПММА/ $\mathrm{CdS}: \mathrm{Ag} \quad\left(\lambda_{L}=400 \mathrm{~nm}\right)$ также наблюдается широкая сложная полоса (рис. 1). Ее основной максимум расположен при длине волны $450 \mathrm{~nm}$. На ниспадающей ветви, в области длин волн $570-580 \mathrm{~nm}$, регистрируется дополнительный максимум. Интенсивность при $\lambda=450 \mathrm{~nm}$ увеличивается с увеличением концентрации ионов $\mathrm{Ag}^{+}$. При концентрации $>5.0 \cdot 10^{-3} \mathrm{~mol} / \mathrm{L}$ происходят обратные изменения. Интенсивность люминесценции существенно уменьшается. Максимум смещается в область длин волн >570 nm. Наблюдающиеся изменения в спектрах и в окраске образцов, происходящие при изменении концентрации ионов $\mathrm{Ag}^{+}$, связаны с образованием различных типов оптических центров. Можно предположить, что при небольших концентрациях ионы $\mathrm{Ag}^{+}$образуют дефекты в структуре кристаллов $\mathrm{CdS}$. Появление

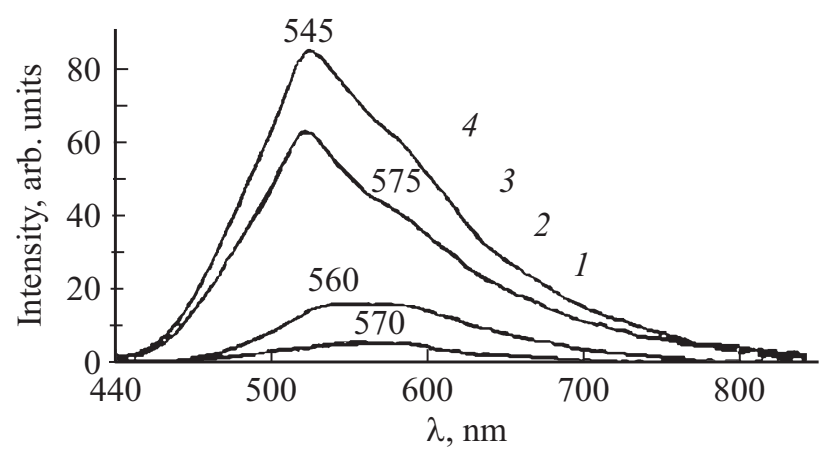

Рис. 1. Спектры люминесценции $\left(\lambda_{L}=400 \mathrm{~nm}\right)$ композиций ПММА/CdS: $\mathrm{Ag}$ с концентрацией ионов $\mathrm{Ag}^{+}(\mathrm{mol} / \mathrm{L})$ в реакционной смеси: $1.0 \cdot 10^{-2}(1), 5.0 \cdot 10^{-3}(2), 5.0 \cdot 10^{-4}(3)$, $1.0 \cdot 10^{-3}(4)$.

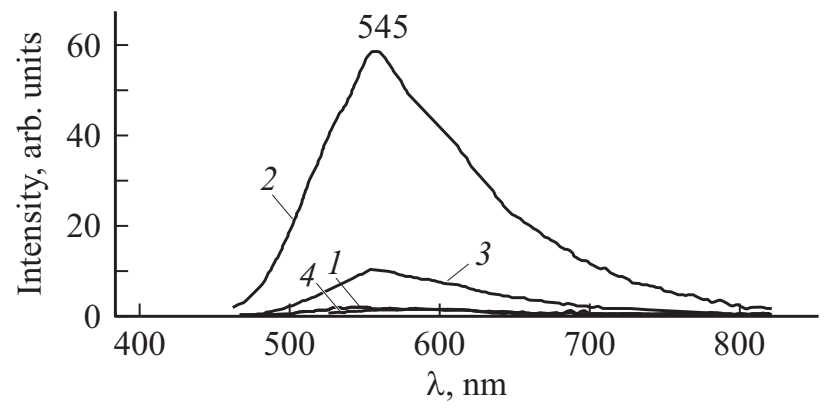

Pис. 2. Спектры люминесценции композиции ПММА/CdS: Ag, зарегистрированные при длине возбуждающго излучения $\left(\lambda_{\mathrm{ex}}\right): 260(1), 400$ (2), 410 (3), $475 \mathrm{~nm}$ (4), $C_{\mathrm{Ag}}=5.0 \cdot 10^{-4} \mathrm{~mol} / \mathrm{L}$ в реакционной смеси.

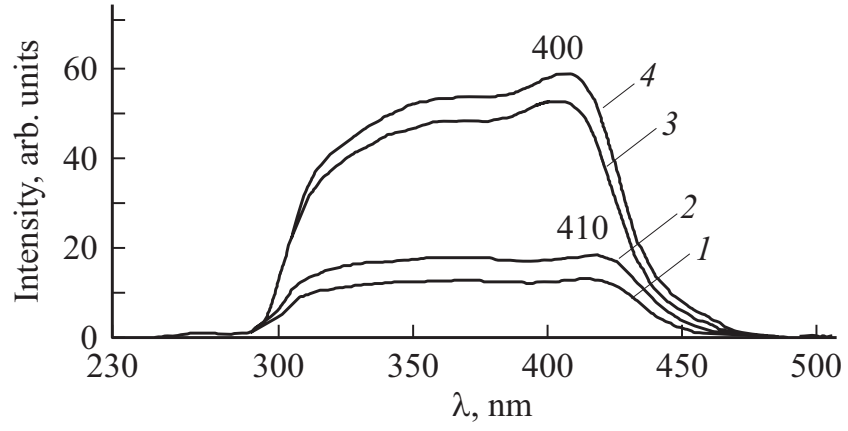

Рис. 3. Спектры возбуждения люминесценции ПММA/CdS: $\mathrm{Ag}$ с содержанием ионов $\mathrm{Ag}^{+}\left(\lambda_{L}, \mathrm{~nm}\right): 1$ и $2-5.0 \cdot 10^{-3} \mathrm{~mol} / \mathrm{L}$ (558 и $540 \mathrm{~nm}$ соответственно), 3 и $4-$ $5.0 \cdot 10^{-4} \mathrm{~mol} / \mathrm{L}$ (536 и $558 \mathrm{~nm}$ соответственно).

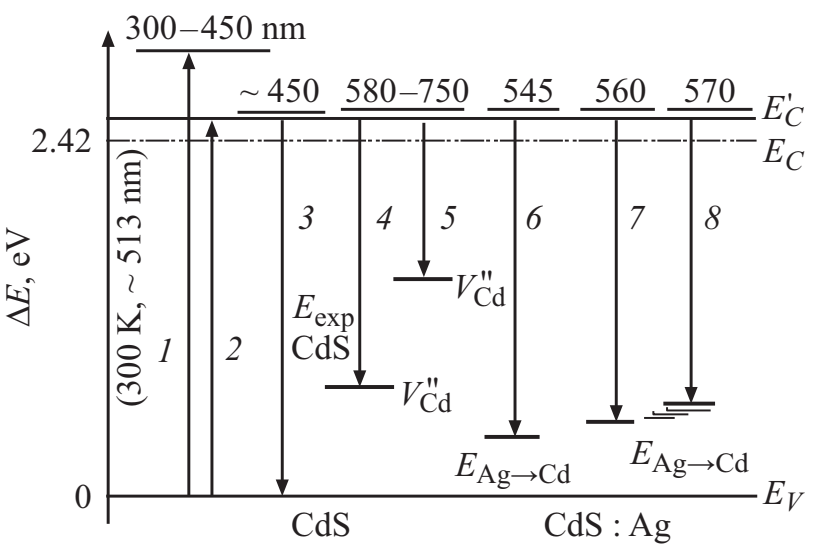

Рис. 4. Схема электронных переходов.

длинноволнового максимума $(570-580 \mathrm{~nm})$ может быть связано с неоднородностью поверхности легированных частиц $\mathrm{CdS}$. C увеличением концентрации ионов $\mathrm{Ag}^{+}$ $\left(>0.50 \cdot 10^{-3} \mathrm{~mol} / \mathrm{L}\right)$ кристаллы CdS оказываются насыщенными ионами $\mathrm{Ag}^{+}$. Преобладает процесс формирования поверхности частиц $\mathrm{CdS}$. Образуются структуры типа „ядро/оболочка“ состава $\mathrm{Cd}(\mathrm{Ag}) \mathrm{S} / \mathrm{Ag}_{2} \mathrm{~S}$. Образование поглощающего слоя $\mathrm{Ag}_{2} \mathrm{~S}$ на поверхности частиц увеличивает их размер и объясняет смещение полосы в длинноволновую часть спектра, а также исчезновение ее коротковолновой компоненты и значительное уменьшение интенсивности люминесценции. Покрывающий кристаллы $\mathrm{Cd}(\mathrm{Ag}) \mathrm{S}$ слой $\mathrm{Ag}_{2} \mathrm{~S}$ нивелирует особенности структуры и „залечивает“ дефекты на поверхности частиц. При изменении длины волны возбуждающего излучения наблюдается спектральная картина, приведенная на рис. 2. Она соответствует высказанным суждениям.

В спектре возбуждения люминесценции композиций ПMМA/CdS: Ag проявляется широкая сложная полоса в интервале длин волн 290-470 nm (рис. 3). Положение полосы и ее вид совпадают с полосой возбуждения люминесценции композиций ПММА/CdS $[18,26]$. Такое совпадение соответствует роли $\mathrm{CdS}$, заключающейся в поглощении энергии и ее передаче на акцепторные 
уровни, образованные ионами $\mathrm{Ag}^{+}$в запрещенной зоне $\mathrm{CdS}$. В наиболее общем виде электронные переходы иллюстрирует схема, приведенная на рис. 4. На схеме $E_{C}$ и $E_{C}^{\prime}-$ положение дна зоны проводимости в монокристалле $\mathrm{CdS}$ и в наночастицах в матрице ПММА. $E_{V}$ - „потолок“ валентной зоны. Переходы 1 и 2 соответствуют поглощению электромагнитного излучения при переходе электронов из валентной зоны $\mathrm{CdS}$ в зону проводимости, 3 - экситонный излучательный переход в наночастицах в полимерной матрице, 4 и 5 - излучательные переходы на уровнях структурно-примесных дефектов на поверхности кристаллов $\mathrm{CdS}\left(V^{\prime \prime}\right)$ [31], 6 - излучательные переходы на уровни, образование которых связано с внедрением ионов $\mathrm{Ag}^{+}$в структуру кристаллов $\mathrm{CdS}$ на позиции ионов $\mathrm{Cd}^{2+}\left(E_{\mathrm{Ag} \rightarrow \mathrm{Cd}}\right)$, 7 и 8 - излучательные переходы на уровни, связанные с формированием поверхности легированных кристаллов $\left(E_{\mathrm{Ag} \rightarrow \mathrm{Cd}}^{\prime \prime}\right)$. Исходя из анализа спектров можно говорить о том, что в легированных кристаллах $\mathrm{CdS}$ уменьшается вероятность энергетических переходов, связанных с излучательной дезактивацией возбужденных состояний через уровни энергии, создаваемые ионами кадмия, серы и кислородом в запрещенной зоне $\mathrm{CdS}$. При этом вероятность дезактивации через уровни, создаваемые с участием ионов $\mathrm{Ag}^{+}$, увеличивается.

\section{Заключение}

Были синтезированы КТ сульфида кадмия, легированного ионами серебра. Полученные структуры закреплены в матрице ПММА. На первом этапе легирования ионы серебра внедряются в кристаллическую структуру $\mathrm{CdS}$. В спектрах проявляются полосы, отнесенные к люминесценции кристаллов $\mathrm{Cd}(\mathrm{Ag}) \mathrm{S}$. Их интенсивность увеличивается при увеличении концентрации ионов серебра до значений $<5.0 \cdot 10^{-3} \mathrm{~mol} / \mathrm{L}$. При дальнейшем увеличении концентрации кристаллическая структура $\mathrm{CdS}$ оказывается насыщенной ионами серебра. Формируется поверхность кристаллов $\mathrm{CdS}$. Образуются частицы состава $\mathrm{Cd}(\mathrm{Ag}) \mathrm{S} / \mathrm{Ag}_{2} \mathrm{~S}$. Интенсивность люминесценции композиций уменьшается. Уменьшение люминесценции связано с поглощением излучения сульфидом серебра, находящимся на поверхности КТ. Взаимное влияние полимерной матрицы и КТ проявляется в реабсорбции излучения.

\section{Список литературы}

[1] Хайрутдинов Р.Ф. // Успехи химии. 1998. Т. 67. № 2. C. 125; Khairutdinov R.F. // Russian Chem. Rev. 1998. V. 67. N 2. P. 109.

[2] Ремпель А.А. // Успехи химии. 2007. Т. 76. № 5. С. 474; Rempel A.A. // Russian Chem. Rev. 2007. V. 76. N 5. P. 435. doi 10.1070/RC2007v076n05ABEH003674

[3] Chandra B.P., Chandra V.K., Jha P. // Solid State Phenomena. 2015. V. 222. P. 1. doi 10.4028/www.scientific.net/SSP.222.1
[4] Denzler D., Olschewski M., Sattler K. // J. Appl. Phys. 1998. V. 84. N 5. P. 2841.

[5] Lozada-Morales R., Zelaya-Angel O., Torres-Delgado G. // Appl. Surface Sci. 2001. V. 175-176. P. 562. doi 10.1016/S0169-4332(01)00115-5

[6] Hayne M., Bansal B. // Luminescence. 2012. V. 27. N 3. P. 179. doi 10.1002/bio. 2342

[7] Sun X., Xie L., Wang T. et. al. // Opt. express. 2013. V. 21. N 7. P. 8214. doi 10.1364/OE.21.008214

[8] Li B., Zhang X., Li L. et. al. // J. Sol. State Chem. 2014. V. 214. P. 108. doi 10.1016/j.jssc.2014.02.009

[9] Ушакова Е.В., Кормилина Т.К., Буркова М.А. и др. // Опт. и спектр. 2017. Т. 122. № 1. С. 31; Ushakova E.V., Kormilina T.K., Burkova M.A. et. al. // Opt. Spectrosc. 2017. V. 122. N 1. P. 25. doi 10.1134/S0030400X17010301

[10] Готовцева Е.Ю., Бирюков А.А., Светличный В.А. // Изв. высш. учебн. завед. Физика. 2013. Т. 56. № 3. С. 32; Gotovtseva E.Y., Biryukov A.A., Svetlichnyi V.A. // Russian Phys. J. 2013. V. 56. N 3. P. 273. doi $10.1007 / \mathrm{s} 11182-013-$ 0027-3

[11] Смагин В.П., Давыдов Д.А., Унжсакова Н.М., Бирюков А.А. // Журн. неорган. хим. 2015. Т. 60. № 12. C. 1734; Smagin V.P., Davydov D.A., Unzhakova N.M., Biryukov A.A. // Rus. J. Inorg. Chem. 2016. V. 60. N 12. P. 1588. doi 10.1134/S0036023615120244

[12] Jing-hua N., Rui-nian H., Wen-lian L. et. al. // J. Phys. D: Appl. Phys. 2006. V. 39. N 11. P. 2357.

[13] Planelles-Aragó J., Julián-López B., Cordoncillo E. et. al. // J. Mater. Chem. 2008. V. 18. P. 5193.

[14] Буланый М.Ф., Коваленко А.В., Полежсаев Б.А., Прокофьев T.A. // ФТП. 2009. Т. 43. Вып. 6. С. 745; Bulanuy M.F., Kovalenko A.V., Polezaev B.A., Prokof'yev T.A. // Semiconductors. 2009. V. 43. N 6. P. 16. doi $10.1134 / \mathrm{S} 1063782609060050$

[15] Огурцов К.А., Бахметьев В.В., Абызов А.М. и др. // Известия СПбГТИ (ТУ). 2010. № 7. С. 13.

[16] Mukherjee P., Shade C.M., Yingling A.M. et al. // J. Phys. Chem. A. 2011. V. 115. N 16. P. 4031. doi 10.1021/jp109786w

[17] Mukherjee P., Sloan R.F., Shade C.M. et. al. // J. Phys. Chem. C. 2013. V. 117. N 27. P. 144514. doi 10.1021/jp404947x

[18] Смагин В.П., Исаева А.А., Еремина Н.С., Бирюков А.А. // Журн. приклад. хим. 2015. Т. 88. Вып. 6. С. 924; Smagin V.P., Isaeva A.A., Eremina N.S., Biryukov A.A. // Rus. J. of Appl. Chem. 2015. V. 88. N 6. P. 1020. doi 10.1134/S1070427215060208

[19] Джсафаров М.А., Насиров Е.Ф., Джсафарли Р.С. // Неорган. матер. 2017. Т. 53. № 1. С. 15; Jafarov M.A., Nasirov E.F., Jafarli R.S. // Inorganic Materials. 2017. V. 53. N 1. P. 39. doi 10.1134/S0020168517010058

[20] Галкин М.В., Агеева Е.В., Недосекин Д.А. и др. // Вестн. Моск. ун-та. Сер. 2. Химия. 2010. Т. 51. № 2. С. 115.

[21] Садовников С.И., Ремпель А.А // Неорган. матер. 2015. T. 51. № 8. C. 829; Sadovnikov S.I., Rempel A.A. // Inorganic Materials. 2015. V. 51. N 8. P. 759. doi 10.1134/S0020168515070134

[22] Садовников С.И., Чукин А.В., Ремпель А.А., Гусев А.И. // ФTT. 2016. T. 58. № 1. С. 32; Sadovnikov S.I., Rempel' A.A., Gusev A.I., Chukin A.V. // Physics of the Solid State. 2016. V. 58. N 1. P. 30. doi 10.1134/S1063783416010273

[23] Акимов И.А. // Опт. и спектр. 1992. Т. 72. № 4. С. 1026. 
[24] Ушаков Н.М., Юрков Г.Ю., Запсис К.В. и др. // Опт. и спектр. 2006. T. 100. № 3. C. 459; Ushakov N.M., Zapsis K.V., Yurkov G.Yu. et. al. // Opt. Spectrosc. 2006. V. 100. N 3. P. 414. doi 10.1134/S0030400X06030180

[25] Звайгзне М.А., Мартынов И.Л., Кривенков В.А. и др. // Опт. и спектр. 2017. Т. 122. № 1. С. 76; Zvaigzne M.A., Martynov I.L., Krivenkov V.A. et. al. // Opt. Spectrosc. 2017. V. 122. N 3. P. 69. doi 10.1134/S0030400X17010313

[26] Смагин В.П., Еремина Н.С., Исаева А.А., Ляхова Ю.В. // Неорган. матер. 2017. Т. 53. № 3. С. 252; Smagin V.P., Eremina N.S., Isaeva A.A., Lyakhova Yu.V. // Inorganic Materials. 2017. V. 53. N 3. P. 263. doi 10.1134/S0020168517030086

[27] Смагин В.П., Давыдов Д.А., Унжсакова Н.М. Патент РФ № $2561287,2015$.

[28] Гутаковский А.К., Покровский Л.Д., Репинский С.М., Свешникова Л.Л. // Журн. структ. хим. 1999. Т. 40. № 3. C. 589.

[29] Бирюков А.А. Автореф. канд. дисс. Томск: ТГУ, 2010. 19 с.

[30] Морозова Н.К., Каретников И.А., Мидерос Д.А. и др. // ФТП. 2006. Т. 40. № 10. С. 1185; Morozova N.K., Karetnikov I.A., Mideros D.A. et. al. // Semiconductors. 2006. V. 40. N 10. P. 1155. doi 10.1134/S106378260610006X

[31] Морозова Н.К., Данилевич Н.Д., Олешко В.И., Вильчинская С.С. // Изв. вузов: Электроника. 2012. № 3 (95). С. 3. 